\title{
Screening of vitamin, mineral and antioxidants in selected vegetables, fruit and grains for the elderly
}

\author{
*Zuwariah, I., Syahida, M., Faridah, H., Rodhiah, R. and Mohd Fakhri, H. \\ Food Science and Technology Research Centre,Malaysian Agricultural Research and Development Institute \\ (MARDI) Headquarters, Persiaran MARDI-UPM, 43400, Serdang, Selangor, Malaysia
}

\author{
Article history: \\ Received: 13 April 2020 \\ Received in revised form: 7 \\ September 2020 \\ Accepted: 26 January 2021 \\ Available Online: 7 February \\ 2021
}

\section{Keywords:}

Vitamin,

Mineral,

Antioxidant,

Vegetables,

Elderly

\section{DOI:}

https://doi.org/10.26656/fr.2017.5(S1).020

\begin{abstract}
Undernutrition and micronutrient deficiency are common in the elderly. Thus, screening of natural food sources for product formulation is important to ensure proper nutrition in older people is being maximized. Selected vegetables, fruit, and grains namely red amaranth, green spinach, barley, corn, pineapple, and Anggun sweet potato were screened for vitamins, minerals and antioxidants. Red amaranth is a good source of vitamin C (375 $\mathrm{mg} / 100 \mathrm{~g})$, Vitamin A (3734 $\mu \mathrm{g} / 100 \mathrm{~g})$, vitamin B1 $(9.01 \mathrm{mg} / 100 \mathrm{~g}), \mathrm{B} 2(672.45 \mu \mathrm{g} / 100$ $\mathrm{g})$, B6 $(10.7 \mathrm{mg} / 100 \mathrm{~g}), \mathrm{B} 9(76.35 \mathrm{mg} / 100 \mathrm{~g})$ and zinc $(12.2 \mathrm{mg} / 100 \mathrm{~g})$. Corn and barley supply minerals such as zinc $(2.65 \mathrm{mg} / 100 \mathrm{~g}$, in corn) and selenium $(50 \mu \mathrm{g} / 100 \mathrm{~g}$ in barley), while pineapple is rich in vitamin $\mathrm{C}(207.16 \mathrm{mg} / 100 \mathrm{~g})$. Total phenolic content (TPC), 2,2-diphenyl-1-picrylhydrazyl (DPPH) and ferric reducing antioxidant power (FRAP) assay have been used to determine antioxidant activity in all samples. The highest radical scavenging activity (DPPH) was found in pineapple. Green spinach contained the highest amount of FRAP, and the highest TPC was found in germinated corn (germinate for $72 \mathrm{hrs}$ ). From this study, it can be concluded that the combination of vegetables, fruit, and grains during food product formulation could provide enough Recommended Nutrient Intake (RNI) for the elderly to maintain a healthy life.
\end{abstract}

\section{Introduction}

Malaysia is facing an ageing population. The people aged 65 and above have increased steadily and today, it is projected from 2.0 million to more than 6.0 million by 2040, according to the Department of Statistics Malaysia. However, despite living longer, the health issues among the elderly become chronic every year. Various age-related diseases are related to undernutrition and micronutrient deficiency among the elderly. It is important to have another approach to ensure proper nutrition in older people optimize with essential vitamins and minerals from natural food sources. Chronic diseases such as cardiovascular diseases, high blood pressure, hypercholesterolemia, osteoporosis, cancers, chronic obstructive pulmonary diseases (COPD), respiratory problems as well as mental illness among the elderly are caused by low intake of fruits and vegetables (World Health Organization, 2002).

Despite lots of health benefits that can be obtained from fruit and vegetables, their intakes are still inadequate especially among the elderly. Therefore, screening of natural food sources is essential to ensure adequate intakes of vitamins and minerals among the elderly based on Malaysian Recommended Nutrient Intake (RNI). Vegetables, fruits, and grains are good sources of antioxidants and they exist both in enzymatic and non-enzymatic forms. Vitamin $\mathrm{C}$ is non-enzymatic antioxidants, while zinc and selenium are known as mineral antioxidants (Barciela et al., 2008). Vitamin and mineral supplements intake are widely used to increase the nutritional status as well as to reduce the micronutrient deficiency in older people. Although some dietary supplements may contain some vitamins and minerals, it would be unwise to assume that they are all efficacious and safe to use.

Thus, food formulation and processing should be considered to achieve Recommended Nutrient Intake (RNI) especially among the elderly. The selection of the ingredients in food formulation from different combinations could provide the reasonable daily recommended amount of the essential nutrients for the maintenance of healthy life and normal body function. Minerals in grains can act as antioxidants and used as nutraceuticals when consumed, by providing the body with protection against cardiovascular, anticancer, anti- 
diabetics and anti-obese agents, immune boosters, chronic inflammatory disorders and degenerative diseases (Rajasekaran et al., 2008). Reduced risk of developing chronic diseases have been associated with regular consumption of whole grains and their products, revealed by some epidemiological studies (Kasum et al., 2002). Whole grains are rich in phytochemical and provide unique bioactive compounds that are complementary to those in fruits and vegetables when consumed together. The additive and synergistic effects of phytochemical in fruits, vegetables and whole grains are responsible for their health benefits (Liu, 2007). Therefore, dietary modification by increasing the consumption of a wide variety of fruits, vegetables, and whole grains daily is said to be a practical strategy for consumers to optimize their health and reduce the risk of chronic diseases.

A healthy diet can boost the immune system in the human body. Thus, foods that are rich with the micronutrients such as zinc, selenium, folic acid, vitamin $\mathrm{A}$, vitamin $\mathrm{B}$, and vitamin $\mathrm{C}$ can alter the immune responses in the body. According to U.S. Department of Agriculture (2016), barley is a good source of many essential vitamins and minerals, including thiamin, niacin, folate, riboflavin, iron, phosphorus, magnesium, zinc, and selenium, all of which are important in maintaining good health and weight control. Sprouted seeds including germinated corn were reported containing a high amount of vitamins and other nutrition (Khalil and Mansour, 1995; Chalorcharoenying et al., 2017). Besides that, vegetables like amaranth, green spinach, and purple sweet potato also high in vitamins (Akanyijuka et al., 2018). Perishable vegetables can contribute to waste problem and when incorporated into food products, it can overcome the problem. Besides, incorporation of pineapple in food formulation will increase the vitamin $\mathrm{C}$ content and can develop the uniqueness of taste when the sweet-sour of pineapple blend with vegetables.

Thus, natural phytochemical and functional foods with possible health-enhancing properties such as vitamins, minerals, and antioxidants, are needed as a whole diet approach in reducing the low intake of micronutrient. Therefore, the objective of this study was to investigate the content of vitamin $\mathrm{A}$, vitamin $\mathrm{C}$, vitamin $\mathrm{B}$, zinc, selenium, and antioxidants in red amaranth, green spinach, barley, corn, pineapple, and also Anggun sweet potato, for the elderly as natural ingredients in products formulation.

\section{Materials and methods}

\subsection{Raw materials}

Red amaranth, green spinach, and pineapple were bought from Pasar Borong Selangor. Corn (Variety hybrid P4546) supplied by MARDI Seberang Perai, Pulau Pinang. Natural pearled Australian barley was bought at the hypermarket. Purple sweet potato (Anggun variety) was supplied by MARDI Bachok, Kelantan. The vegetables were being sorted from any defect like bruising, discolouration of leaves, or mould. Morris pineapple (Ananas comosus L.) pulps were used to produce the pineapple powder. The vegetable leaves, pineapple pulp and purple sweet potato pulp were washed in filtered water and then dried in the oven dryer (Memmert, Germany) at $60^{\circ} \mathrm{C}$ for $17 \mathrm{hrs}$. After that, the dried plant samples have been ground well into a fine powder by using a mixer grinder (Panasonic MX-900M), they were stored in aluminium pack at room temperature.

\subsection{Germinated corn and barley}

The corn and barley seeds were being washed with filtered tap water, three times, then the samples were being soaked in filtered tap water and proceed with the germination process starting from $0 \mathrm{hr}$ (initial seeds) as a control sample until $72 \mathrm{hrs}$ for corn and $48 \mathrm{hrs}$ for barley (Zuwariah et al., 2017). The barley sample turned mouldy after $48 \mathrm{hrs}$, and the sample was discarded. Next, the seeds have been dried in a forced draft oven (Memmert, Germany) at $60^{\circ} \mathrm{C}$. The dried samples have been milled into powder using a grinder (Panasonic MX$900 \mathrm{M}$ ) and used for the analysis.

\subsection{Total phenolic content}

Total phenolic content was determined following the method by Lim et al. (2007) by using Folin-Ciocalteu reagent and expressed in gallic acid equivalents ( $\mathrm{g}$ per $100 \mathrm{~g}$ samples). Estimation of the phenolic compounds was carried out in triplicate.

\subsection{Antioxidant activity}

The evaluation of antioxidant capacity in each sample was carried out following the method by Alothman et al. (2009). The free radical scavenging effect was determined based on the 2,2-diphenyl-1picrylhydrazyl (DPPH) assay. About $1.0 \mathrm{~mL}$ sample extracts were added with $2.0 \mathrm{~mL}$ freshly prepared methanolic DPPH solution (20 ppm). The mixture was then thoroughly vortex-mixed and left to stand for 30 min in the dark. By using a UV-VIS spectrophotometer (Hitachi U-2800 Japan) against methanol as a blank for auto-zero, the absorbance was recorded at $517 \mathrm{~nm}$ and the percentage of inhibition of the DPPH radical was 
expressed by the antioxidant activity and calculated as below:

$$
\% \text { Scavenging activity }=\frac{\text { Abs control }-(\text { Abs sample }- \text { Abs blank })}{\text { Abs control }} \times 100
$$

Where Abs control is the absorbance of DPPH solution without sample extracts and Abs blank is the absorbance of sample extracts without DPPH solution.

\subsection{Ferric reducing antioxidant power assay (FRAP)}

The ability of the antioxidant as a reducing agent was determined using ferric reducing antioxidant power assay (FRAP). About $40 \mu \mathrm{L}$ sample extract was mixed with $3.0 \mathrm{~mL}$ FRAP reagent. The mixture was left in the dark for 30 mins at $37^{\circ} \mathrm{C}$ and by using distilled water, the absorbance was determined at $593 \mathrm{~nm}$ against blank. By mixing $2.5 \mathrm{~mL}$ of $10 \mathrm{mM} \mathrm{2,4,6-tris(1-pyridyl)-5-triazine}$ (TPTZ) solution in $40 \mathrm{mM} \mathrm{HCl}$ with $2.5 \mathrm{~mL}$ of $20 \mathrm{mM}$ $\mathrm{FeCl}_{3}$ and $25 \mathrm{~mL}$ of $0.3 \mathrm{M}$ acetate buffer (pH 3.6), FRAP reagent should be freshly prepared. A calibration curve using ferrous sulphate $\left(\mathrm{FeSO}_{4}\right)$ was prepared. FRAP value was expressed as $\mathrm{g} \mathrm{FeSO}_{4} / 100 \mathrm{~g}$ on a dry basis.

\subsection{Analysis of vitamin $B$}

\subsubsection{Reagents}

The analytical grade of reagent and standard were used as followed, Cyanocobalamin (B12) (Sigma), pyridoxine (B6) (Sigma), thiamine (B1) (Supelco), riboflavin (B2) (Supelco) and folic acid (B9) (Supelco). Trifluoroacetic acid (TFA) was obtained from Merck (Geneva, Switzerland). Water was being purified using a Milli-Q system from Millipore (Le Mont-sur-Lausanne, Switzerland). The protease enzyme was used. All other reagents used were analytical grade.

\subsubsection{Vitamin B extraction}

By using 250mL Erlenmeyer Flask, the samples $(10 \mathrm{~g})$ were accurately weighed and under agitation, 50 $\mathrm{mL}$ of Acetonitrile: Acetic acid: Water (50: 10: 940) and $0.2 \mathrm{~mL}$ protease were added. The solution was then incubated at $37^{\circ} \mathrm{C}$ for $16 \mathrm{hrs}$ under dark conditions. The solution was filtered through a folded filter paper (Whatman Grade 2) and it was filtered again through a micropore filter $(0.45 \mu \mathrm{m})$, after being cooled at room temperature.

\subsubsection{Preparation of standard stock solutions}

By using the HPLC system, $20 \mu \mathrm{L}$ of the filtrate were injected. Quantification of vitamin B1, B2, B6, B9, and $\mathrm{B} 12$ was accomplished by comparison to vitamin $\mathrm{B}$ standards. The standard stock solutions for thiamine, riboflavin, and pyridoxine were prepared (Aslam et al., 2008). The standard stock solution for vitamin B9 was prepared by dissolving $10 \mathrm{mg}$ of folic acid in $25 \mathrm{~mL}$ ethanol: $0.1 \mathrm{~N}$ hydrochloric acids (1:1). The standard solution for B12 was prepared by dissolving $25 \mathrm{mg}$ of cyanocobalamin in $25 \mathrm{~mL}$ ethanol (25\%) (Aslam et al., 2008).

\subsubsection{Analysis of vitamin B using HPLC}

The analysis of sample was performed by High Performance Liquid Chromatography (HPLC), by Waters Alliance HPLC System. The waters symmetry C18 column $(4.6 \times 250 \mathrm{~mm} 5 \mu \mathrm{m})$ was used. The mobile phase consists of $0.1 \%$ Trifluoroacetic acid in water (eluent A) and $0.1 \%$ Trifluoroacetic acid in acetonitrile (eluent B) for analysis of vitamin B1 and B6 (Group 1). Different mobile phase was used for vitamin B2, B9, and B12 (Group 2). For group 2, eluent A was $10 \mathrm{mM}$ Potassium dihydrogen phosphate $\left(\mathrm{KH}_{2} \mathrm{PO}_{4}\right), \mathrm{pH} 6$ and eluent B was $100 \%$ acetonitrile $(\mathrm{v} / \mathrm{v})$. The UV detector and fluorescence detector were employed for detection of peaks, using wavelength of $246 \mathrm{~nm}, 290 \mathrm{~nm}, 280.6$ $\mathrm{nm}, 359.9 \mathrm{~nm}$, and $210 \mathrm{~nm}$. Analysis of vitamin B was done in triplicate (Aslam et al., 2008).

\subsection{Methods of vitamin A, vitamin $C$ and minerals analyses}

Methods of vitamin A and vitamin C were based on Ismail and Fun (2003). The mineral was determined according to the in-house method based on the Association of Official Analytical Chemists (2012) (Chapter 9, method 9.1.09 and Chapter 50, method 50.1.14).

\subsection{Statistical analysis}

All data were expressed as mean and were done in triplicate independent analyses. Data were analyzed using SAS 9.3 (SAS Institute Inc., USA) for ANOVA.

\section{Results and discussion}

\subsection{Vitamin and mineral analysis}

The source of ingredients during food formulation is closely related to the role of diet and nutrition in healthy ageing. According to Figure 1, the germination of corn and barley changes the content of vitamin B-group. Thiamine (Vitamin B1) content increased during the germination of corn. The 48-hr germinated corn increased of thiamine by about 4.6 folds compared to barley sprouts. The same trend was found in riboflavin (Vitamin B2) after $72 \mathrm{hrs}$ of the germination process. The amount of riboflavin was highest in germinated corn at $72 \mathrm{hrs}(302 \mu \mathrm{g} / 100 \mathrm{~g})$, or 3.6 times folds if compared with initial corn. Zieliński et al. (2006) showed an almost linear reduction in thiamine content during rapeseed germination $(0.5 \mathrm{mg} / 100 \mathrm{~g}$ reduced to 0.15 $\mathrm{mg} / 100 \mathrm{~g}$ ) and it was different from this study. However, the gradual increase of riboflavin content in rapeseed 

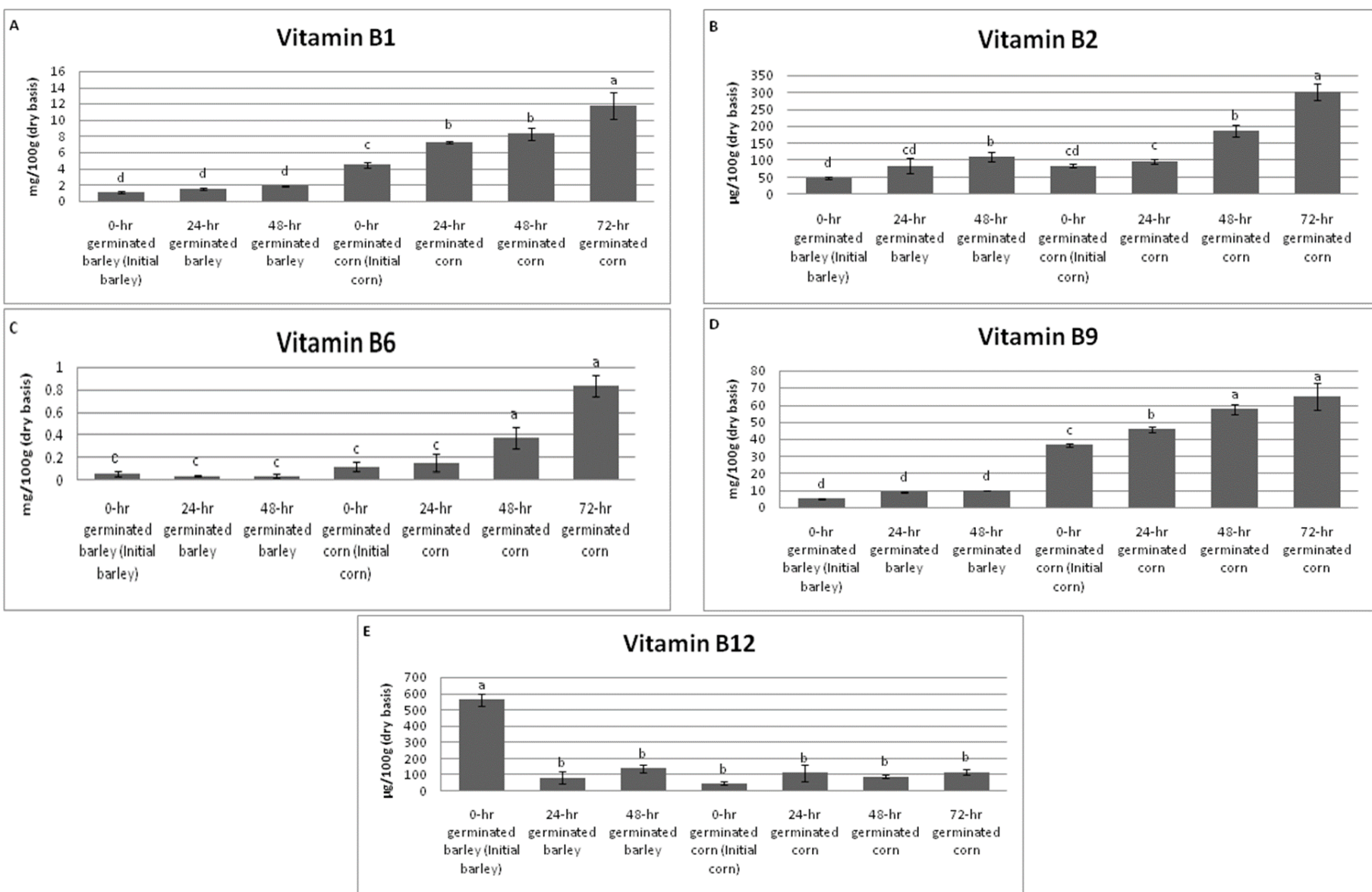

Figure 1. Vitamin B contents of germinated barley and corn; (A) Vitamin B1, (B) Vitamin B2, (C) Vitamin B6, (D), Vitamin B9, and (E) Vitamin B12. Bars with the same letter are not significantly different $(p>0.05)$

sprouts throughout the germination $(0.09 \mathrm{mg} / 100 \mathrm{~g}$ increased to $0.34 \mathrm{mg} / 100 \mathrm{~g}$ ), and it was found to have a similar trend with barley and corn from this study.

On the other hand, the $72 \mathrm{hrs}$ germination process did not affect (significantly) in pyridoxine (Vitamin B6) content of sprouted barley but increased significantly in corn after $48 \mathrm{hrs}(0.37 \mathrm{mg} / 100 \mathrm{~g})$ and $72 \mathrm{hrs}(0.84$ $\mathrm{mg} / 100 \mathrm{~g}$ ) of germination. This finding was the same variation with Lao et al. (2019) and they found that vitamin B6 in yellow corn and yellow sweet corn was $0.622 \mathrm{mg} / 100 \mathrm{~g}$ and $0.093 \mathrm{mg} / 100 \mathrm{~g}$ respectively. Aslam et al. (2008) found that vitamin B-group contents were directly influenced by the seedlings age and germinating conditions. They found that vitamin B6 was $0.022 \mathrm{mg} / 100 \mathrm{~g}$ in germinated chickpea. Similarly, germination significantly increased folic acid (Vitamin B9) in corn (1.78 times folds) after $72 \mathrm{hrs}$ of sprouts (65 $\mathrm{mg} / 100 \mathrm{~g}$ ) when compared with initial corn. The vitamin B9 content of white sweet corn from Guangzhou, China was $46 \mu \mathrm{g} / 100 \mathrm{~g}$ on a wet basis (Lao et al., 2019). The variation of vitamin B9 content is attributable to fertilizer, species (Mozafar, 1994), and dry or wet basis of samples. The contents of cyanocobalamin (Vitamin B12) dropped drastically in barley after $48 \mathrm{hrs}$ of germination by about 4 folds compared with initial barley. The highest amount of cyanocobalamin content has been found in initial barley which was $560 \mu \mathrm{g} / 100 \mathrm{~g}$ if compared to sprouted corn. "Tempe" or also known as a fermented soybean-based food, contains a considerable amount of Vitamin B12 $(0.7-8.0 \mu \mathrm{g} / 100 \mathrm{~g})$ (Nout, and Rombouts, 1990). Overall, many researchers studied vitamin content changes in legumes during germination and they found that there was an inconsistency of vitamin during the germination process. Many factors were affecting the contents of vitamins such as the number of rinses, light levels, and the time for seed germination (Prodanov et al., 1997; Bains et al., 2011; Zieliński et al., 2006).

Germinated corn at $72 \mathrm{hrs}$ (Vitamin B1: 11.77 $\mathrm{mg} / 100 \mathrm{~g}$ and vitamin B9: $64.97 \mathrm{mg} / 100 \mathrm{~g}$ ) has achieved the elderly RNI (RNI Malaysia) for vitamin B1 (RNI: 1.1 $-1.2 \mathrm{mg} /$ day) and B9 (RNI: $400 \mu \mathrm{g} /$ day), while initial barley (Vitamin B12: $560.85 \mu \mathrm{g} / 100 \mathrm{~g}$ ) achieved the RNI in vitamin B12 content (RNI: $4 \mu \mathrm{g} /$ day), based on Figure 1. Thus, different combinations of the natural raw ingredient could provide a reasonable daily recommended amount of essential nutrients for the maintenance of healthy life among the elderly.

Vitamin and mineral contents in selected vegetables, pineapple, barley, and corn are shown in Table 1. From Figure 1, initial barley and 72-hr germinated corn were selected as the best source of vitamin B for cereals based on Recommended nutrient intakes (RNI) for Malaysia 


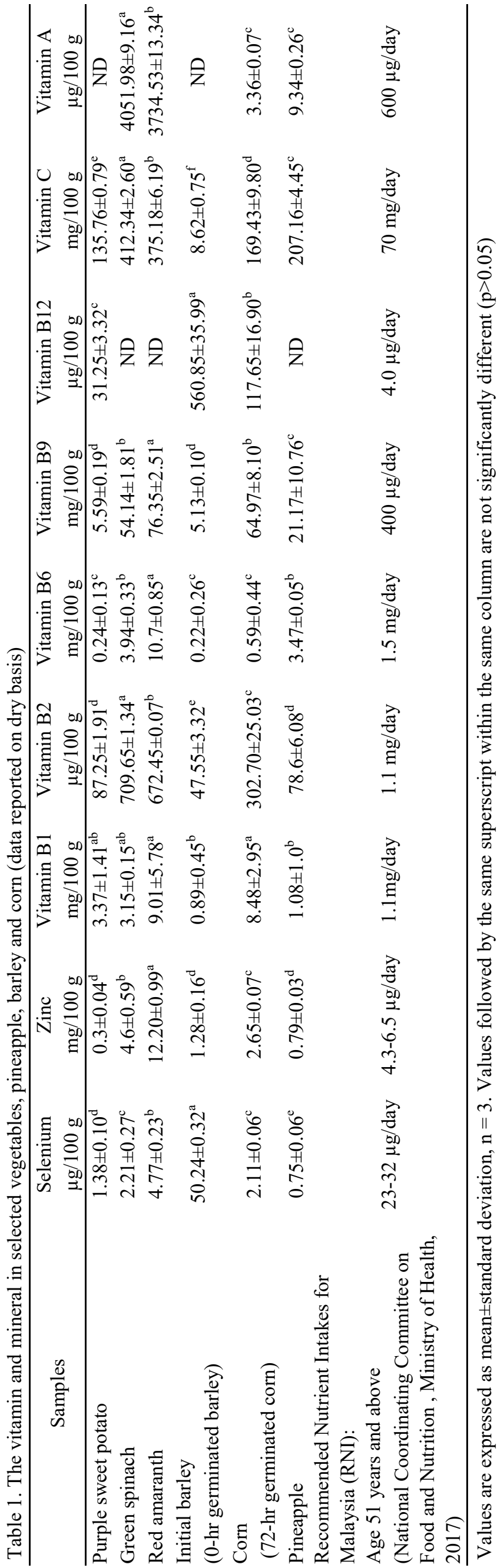


(Table 1). Overall, RNI for Malaysian is $1.1 \mathrm{mg}$ /day for vitamin B1 and B2, vitamin B6 is $1.5 \mathrm{mg} /$ day, vitamin $\mathrm{B} 9$ is $400 \mu \mathrm{g} / \mathrm{day}$, vitamin B12 is $4.0 \mu \mathrm{g} /$ day, and zinc is 4.3 to $6.5 \mathrm{mg} /$ day. The results showed that almost all samples (Table 1) contain an appreciable amount of essential nutrients. Red amaranth had the highest content of Zinc $(12.2 \mathrm{mg} / 100 \mathrm{~g})$, Vitamin B1 $(9.01 \mathrm{mg} / 100 \mathrm{~g})$, Vitamin B6 (10.70 mg/100 g), and Vitamin B9 (76.35 $\mathrm{mg} / 100 \mathrm{~g}$ ) and these contents achieved RNI for the elderly. Processed cereals and polished rice have a moderate zinc content, typically between 10 to $25 \mathrm{mg} / \mathrm{kg}$. Fish, roots and tubers, green leafy vegetables, and fruits are only modest sources of zinc, having concentrations $<10 \mathrm{mg} / \mathrm{kg}$ (Sandström, 1989). According to Mocchegiani et al. (2013), old people age 60-65 years and above had zinc intakes below $50 \%$ of the recommended daily allowance. Zinc is essential for the elderly because of its impact on biological, biochemical, and immune functions if to be compared with other micronutrients (Shankar and Prasad, 1998; Mocchegiani et al., 1998; Haase et al., 2006). Van der Walt et al. (2009) has found that the vitamin B9 content of Amaranthus sp from three locations in South Africa was ranged from 72 to $130 \mu \mathrm{g} / 100 \mathrm{~g}$ of the fresh sample. The variation in folate (Vitamin B9) values could be a result of post-harvest conditions of the raw materials, a variety of vegetables used, or differences in analytical methods (Ejoh et al., 2019).

The source of riboflavin $(709.65 \mu \mathrm{g} / 100 \mathrm{~g})$, vitamin C $(412.34 \mathrm{mg} / 100 \mathrm{~g})$, and vitamin A $(4051 \mu \mathrm{g} / 100 \mathrm{~g})$ were found in green spinach and the amount of these vitamins has achieved RNI for the elderly. Vitamin C content of green spinach was about 5.8 folds while vitamin A provided 6.8 folds higher than RNI for Malaysian. According to Nutrient Composition of Malaysian Foods, Chinese mustard, Chinese kale, lettuce, spinach, and swamp cabbage have been found to contain about $1825-4760 \mu \mathrm{g}$ of vitamin A / $100 \mathrm{~g}$ edible portion, $27.6-107 \mathrm{mg}$ of vitamin $\mathrm{C} / 100 \mathrm{~g}$ edible portion, and $0.15-0.55 \mathrm{mg}$ of riboflavin $/ 100 \mathrm{~g}$ edible portion (Tee et al., 1997). Besides Riddoch et al. (1998) have found that the vitamin $\mathrm{C}$ contents of mung beans, green lentils, fenugreek, and black-eyed beans ranged between 140 and $200 \mathrm{mg} / \mathrm{g}$ fresh weight after 4 days germination. They also studied the effect of boiling water on vitamin $\mathrm{C}$ concentrations in sprouted beans. About $65 \%$ of vitamin $C$ decreased within 5 min when they were immersed in boiling water. Losses continued thereafter but at a slower rate. According to Ahmad et al. (2007), vitamin A content in carrots was $11210 \mu \mathrm{g} / 100$ $\mathrm{g}$, and tomato was $1610 \mu \mathrm{g} / 100 \mathrm{~g}$. Due to differences in sources of vitamin A, there might be slight differences in the data in terms of experimental condition, extraction procedures, and method used. Variation in ecological growth conditions like variety and environmental aspects may also be contributing factors (Aremu and Nweze, 2017). The selenium and vitamin B12 content was significantly found in barley, with $50.24 \mu \mathrm{g} / 100 \mathrm{~g}$ and $560.85 \mu \mathrm{g} / 100 \mathrm{~g}$ respectively, and also achieve RNI for the elderly. The differences in mineral contents among different seeds may be due to differences in species or the germination process (Zieliński et al., 2006).The dietary sources of Vitamin B12 are animal-derived foods, although a few plant-based foods contain substantial amounts of vitamin B12, based on research made by several researchers (Squires et al., 1992; Sato et al., 1997; Watanabe et al., 2014). Due to the fact that the animal-based food contained saturated fat, high cholesterol, and antibiotic, plant-derived foods that contain high levels of Vitamin B12 is necessary for geriatric food. Plant-based vitamin B12 sources depend on various factors such as fertilizer or vitamin B12 soaking solutions. Mozafar (1994) found that by adding an organic fertilizer such as cow manure, it will significantly increase the Vitamin B12 content of spinach leaves $(0.14 \mu \mathrm{g} / 100 \mathrm{~g}$ fresh weight). The best source of Vitamin B12 for consumption will be barley, but due to certain circumstances such as the processes that expose foods to high levels of heat, light, or oxygen, it can cause the greatest nutrient loss.

\subsection{Antioxidant activity}

In order to determine the antioxidant activity in all samples, total phenolic content (TPC), 2,2-diphenyl-1picrylhydrazyl (DPPH), and ferric reducing antioxidant power (FRAP) assay have been used. Based on Figure 2, the highest total phenolic content was exhibited by $72-\mathrm{hr}$ germinated corn if to be compared to others. The trends of total phenolic content in all samples were in order of 72-hr germinated corn $>48$-hr germinated corn $>$ green spinach $>$ pineapple $>$ red amaranth $>$ purple sweet potato $>24$-hr germinated corn $>$ germinated barley at 48 hrs $>$ initial barley $>$ initial corn $>24$-hr germinated barley.

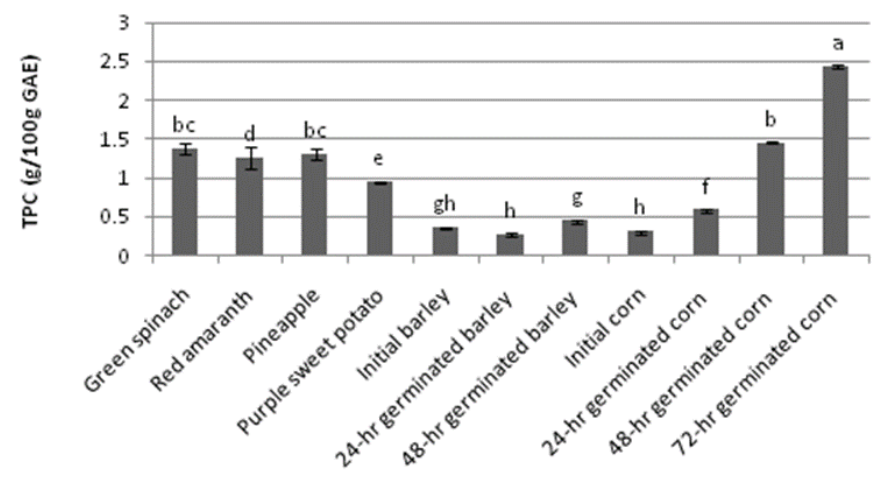

Figure 2. Total phenolic content in green spinach, red amaranth, pineapple purple sweet potato, germinated barley and germinated corn. Bars with different letters are significantly different $(\mathrm{p}<0.05)$. Vertical bars indicate \pm SD. 
The excellent source of phenolic antioxidants was in agreement with the previous study (Polthum and Ahromrit, 2014). They have reported that germinated Thai waxy corn seeds contained a higher amount of dietary phenolic antioxidants than non-germinated corn seeds. Many studies were reported that corn seed contains ferulic acid in its structure, thus it's also known as a phenolic antioxidant (Patel and Naik, 2004). Earlier studies have reported that germination effects on reduction of antioxidant activity in the germinated seeds (Oboh, 2006; Lopez et al., 2006). The impact of germination on phenolic content and antioxidant activity in 13 edible seed species (mungbean, alfalfa, fava, fenugreek, mustard, wheat, broccoli, sunflower, soybean, radish, kale, lentil, and onion) were analyzed (Cevallos and Cisneros, 2010). Cevallos and Cisneros (2010) found that phenolics content increased from dormant seed to 7 days sprouted seed and the value ranged from 490 $\mathrm{mg} / 100 \mathrm{~g}$ (lentil) to $5676 \mathrm{mg} / 100 \mathrm{~g}$ (mustard). Our findings show a similar trend with those of López Amorós et al. (2006) and Gharachorloo et al. (2012), which indicated that germination modified the quantity and quality of phenolic compounds of legumes that underwent a significant increase in antioxidant activity after 5 days of germination. Therefore, germinated corn could be used as a source of natural antioxidants.

The germination process is also involved in water absorption by dry seed during the soaking process. Water activates gibberellic acids in the germ. The mobility of water act as transport for gibberellic acids to move from the embryo to the aleurone layer as molecular signals. Then enzymes such as carbohydrase, protease, and lipase are synthesized and secreted into the endosperm. The respiration process of the seed occurs, involve degradation of starch, proteins, and lipid and synthesis of new cell constituents such as phenolic compounds. During the process of germination, the phenolic compound will change. In the cell wall of seeds, the nonextractable phenolic compounds are breakdown while new varieties of bound phenolic compounds are synthesized from the soluble free phenolic compound. Thus, the complete transformation of seed germination develops the shoot and rootlets (Nelson et al., 2013; Sangsukiam and Duangmal, 2017).

Figure 3 shown pineapple constitutes the highest DPPH radical scavenging activity. The other samples were in decreasing order as follows: 72-hr germinated corn $>$ purple sweet potato $>$ green spinach $>$ red amaranth $>$ initial barley $>48$-hr germinated corn $>24$ hr germinated corn $>24-\mathrm{hr}$ germinated barley $>$ initial corn $>48-\mathrm{hr}$ germinated barley. The DPPH radical scavenging activity in the barley was gradually decreased during the germination period. On the contrary, corns undergo a significant increase in antioxidant activity after germination. This result is in the line as reported by López Amorós et al.(2006). They found that antioxidant activity in peas and beans increases significantly after germination whereas lentils show a decrease.

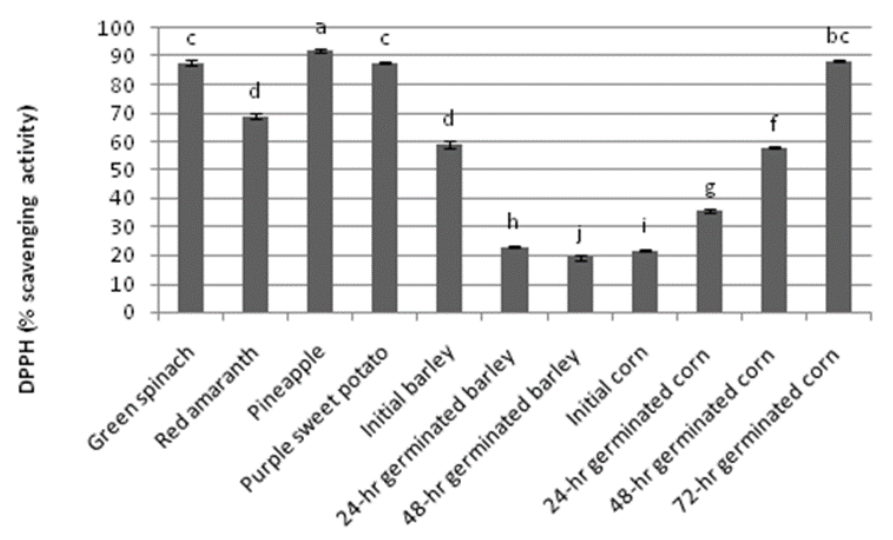

Figure 3. DPPH radical scavenging activity in green spinach, red amaranth, pineapple purple sweet potato, germinated barley and germinated corn. Bars with different letters are significantly different $(\mathrm{p}<0.05)$. Vertical bars indicate \pm SD.

Green spinach, red amaranth, pineapple, and sweet potato was found to be more effective as DPPH radical scavenger $(68.9 \%$ - 91.96\%) if compared with vegetable samples studied by Gacche et al. (2010). They found that cauliflower had $67.2 \%$ DPPH radical scavenger, cabbage had $42.4 \%$, spinach had $20.4 \%$, lady's finger had $43.8 \%$ and brinjal had $51.6 \%$.

The highest capacity for $\mathrm{Fe}^{3+}$ reduction was found in green spinach followed by red amaranth $>$ pineapple $>$ purple sweet potato $>$ initial barley $>24-\mathrm{hr}$ germinated corn $>$ initial corn $>24-\mathrm{hr}$ germinated barley $>48-\mathrm{hr}$ germinated barley $>48-\mathrm{hr}$ germinated corn $>72-\mathrm{hr}$ germinated corn (Figure 4). According to Sreeramulu et al. (2013), the FRAP contents in cereals and millets ranged $0.450-13.093 \mathrm{~g} / 100 \mathrm{~g}$, while FRAP activity in green leafy vegetables ranges $1.380-27.827 \mathrm{~g} / 100 \mathrm{~g}$. They found that spinach had $1.38 \mathrm{~g} / 100 \mathrm{~g}$ FRAP activity, and this value lower than the green spinach and red

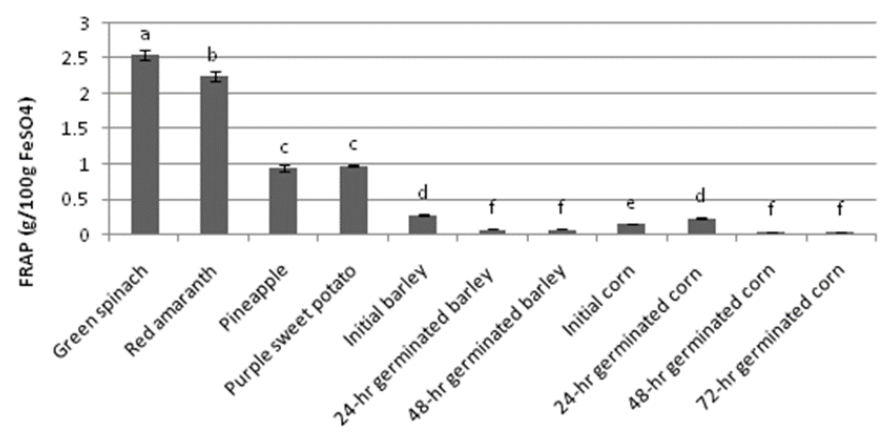

Figure 4. FRAP content in green spinach, red amaranth, pineapple purple sweet potato, germinated barley and germinated corn. Bars with different letters are significantly different $(\mathrm{p}<0.05)$. Vertical bars indicate \pm SD. 
amaranth found in this study. The variation range in the FRAP content was reported in a few vegetables from other parts of the world. It might be caused by the cooking method affected the number of antioxidant compounds and also the production of stronger radicalscavenging antioxidants by thermal or chemical reactions (Bajpai et al., 2005).

\section{Conclusion}

In the present study, the germination of corn increased the amount of B vitamin. Barley seed is a good source of vitamin B12. Besides that, it also contains zinc and selenium as a mineral antioxidant. Red amaranth is a good source of vitamin C, Vitamin A, vitamin B complex, and zinc. Pineapple, green spinach, and $72 \mathrm{hrs}$ of germinated corn were also found to have high in TPC and DPPH. The selection of raw ingredients is very important because they contribute to a healthy diet and complete nutrition among the elderly. In order to achieve the maximum recommended daily intake, there is a need to provide scientific data on natural ingredients and processing techniques in product formulation. Therefore, the nutrients found in all selected vegetables and grains are in variable concentrations and for normal body function as well as for healthy life, their consumption in different combinations is suggested.

\section{Acknowledgement}

The authors would like to acknowledge the financial support provided by Projek Pembangunan MARDI, MOA.

\section{References}

Aremu, S.O. and Nweze, C.C. (2017). Determination of vitamin A content from selected Nigerian fruits using spectrophotometric method. Bangladesh Journal of Scientific and Industrial Research, 52(2), 153-158. https://doi.org/10.3329/bjsir.v52i2.32940

Aslam, J. Mohammed, S.M., Saeed, A.K. and Abdul, Q.K. (2008). HPLC analysis of water-soluble vitamins (B1, B2, B3, B5, B6) in in vitro and ex vitro germinated chickpea (Cicer arietinum L.). African Journal of Biotechnology, 7(14), 2310-2314.

Association of Official Analytical Chemists (2012). Official Methods of Analysis. 19th ed. Virginia: AOAC.

Alothman, M., Bhat, R. dan Karim, A.A. (2009). Antioxidant capacity and phenolic content of selected tropical fruits from Malaysia, extracted with different solvents. Food Chemistry, 115(3), 785 788. https://doi.org/10.1016/j.foodchem.2008.12.005

Akanyijuka, S.A., Acham, H., Tumuhimbise, G.T.,
Namutebi, A., Masanza, M., Jagwe, J.N., Kasharu, A., Kizito, B., Rees, E.D. (2018). Effect of Different Processing Conditions on Proximate and Bioactive Contents of Solanum aethiopicum (Shum) Powders and Acceptability for Cottage Scale Production. American Journal of Food and Nutrition, 6, 46-54.

Bains, K., Uppal, V. and Kaur, H. (2014). Optimization of germination time and heat treatments for enhanced availability of minerals from leguminous sprouts. Journal of Food Science and Technology, 51, 1016-1020. https://doi.org/10.1007/s13197-0110582-y

Bajpai, M., Mishra, A. and Prakash, D. (2005). Antioxidant and free radical scavenging activities of some leafy vegetables. International Journal of Food Science and Nutrition, 56(7), 473-481. https:// doi.org/10.1080/09637480500524299

Barciela, J., Herrero, C., García-Martín, S. and Peña, R.M. (2008). A Brief Study of The Role Of Selenium As Antioxidant. Electronic Journal of Environmental, Agricultural and Food Chemistry, 7 (8), 3151-3155.

Cevallos-Casals, B.A. and Cisneros-Zevallos, L. (2010). Impact of germination on phenolic content and antioxidant activity of 13 edible seed species. Food Chemistry, 119(4), 1485-1490. https:// doi.org/10.1016/j.foodchem.2009.09.030

Chalorcharoenying, W., Lomthaisong, K., Suriharn, B. and Lertrat, K. (2017). Germination process increases phytochemicals in corn. International Food Research Journal, 24(2), 552-558.

Ejoh, S.I., Wireko-Manu, F.D., Page, D. and Renard C.M.G. (2019). Estimation of folate content of cultivated and uncultivated traditional green leafy vegetables in Nigeria. African Journal of Food Science, 13(9), 191-195. https://doi.org/10.5897/ AJFS2019.1784

Gacche, R.N., Kabaliye, V.N., Dhole, N.A. and Jadhav, A.D. (2010). Antioxidant potential of selected vegetables commonly used in diet in Asian subcontinent. Indian Journal of Natural products and Resources, 1(3), 306-313.

Gharachorloo, M., Tarzi, B.G., Baharinia, M. and Hemaci, A.H. (2012). Antioxidant activity and phenolic content of germinated lentil (Lens culinaris). Journal of Medicinal Plants Research, 6 (30), 4562-4566.

Haase, H., Mocchegiani, E. and Rink L. (2006). Correlation between zinc status and immune function in the elderly. Biogerontology, 7, 421-428. https://doi.org/10.1007/s10522-006-9057-3

Ismail, A. and Fun, C.S. (2003). Determination of 
vitamin $\mathrm{C}$, beta carotene and riboflavin contents in five green vegetables organically and conventionally grown. Malaysian Journal of Nutrition, 9(1), 31-39.

Kasum, C.M., Jacobs, D.R.J., Nicodemus, K. and Folson, A.R. (2002). Dietary risk factors for upper aerodigestive tract cancers. International Journal of Cancer, 99(2), 267-272. https://doi.org/10.1002/ ijc. 10341

Khalil, A.H. and Mansour, E.H. (1995). The effect of cooking, autoclaving and germination on the nutritional quality of faba beans. Food Chemistry, 54 (2), 177-182. https://doi.org/10.1016/0308-8146(95) 00024-D

Lim, Y.Y., Lim, T.T. and Tee., J.J. (2007). Antioxidant properties of several tropical fruits: A comparative study. Food Chemistry, 103(3), 1003-1008. https:// doi.org/10.1016/j.foodchem.2006.08.038

Liu, R.H. (2007). Whole grain phytochemicals and health. Journal of Cereal Science, 46(3), 207-219. https://doi.org/10.1016/j.jcs.2007.06.010

Lopez-Amoros, M.L., Hernandez, T. and Strella, I. (2006). Effect of germination on legume phenolic compounds and their antioxidant activity. Journal of Food Composition and Analysis, 19(4), 277-283. https://doi.org/10.1016/j.jfca.2004.06.012

Mocchegiani, E., Muzzioli, M., Cipriano, C. and Giacconi R. (1998). Zinc, T-cell pathways, aging: role of metallothioneins. Mechanisms of Ageing and Development, 106(1-2), 183-204. https:// doi.org/10.1016/S0047-6374(98)00115-8

Mocchegiani, E., Romeo, J., Malavolta, M., Costarelli, L., Giacconi, R., Diaz, L.E. and Marcos, A. (2013). Zinc: dietary intake and impact of supplementation on immune function in elderly. $A G E, 35(3), 839-860$. https://doi.org/10.1007/s11357-011-9377-3

Mozafar, A. (1994). Enrichment of some B-vitamins in plants with application of organic fertilizers. Plant Soil, 167, 305-311. https://doi.org/10.1007/ BF00007957

National Coordinating Committee on Food and Nutrition, Ministry of Health Malaysia. (2017). Recommended Nutrient Intakes for Malaysia. A Report of the Technical Working Group on Nutritional Guidelines. Malaysia: National Coordinating Committee on Food and Nutrition (NCCFN) Ministry of Health Malaysia.

Nelson, K., Stojanovska, L., Vasiljevic, T. and Mathai, M. (2013). Germinated grains: A superior whole grain functional food. Canadian Journal of Physiology and Pharmacology, 91(6), 429441.https://doi.org/10.1139/cjpp-2012-0351.

Nout, M.J.R. and Rombouts, F.M. (1990). Recent developments in tempe research. Journal of Applied Bacteriology, 69(5), 609-633. https:// doi.org/10.1111/j.1365-2672.1990.tb01555.x

Oboh, G. (2006). Antioxidant properties of some commonly consumed and underutilized tropical legumes. European Food Research and Technology, 224, 61-65. https://doi.org/10.1007/s00217-0060289-x

Patel, M. and Naik, S.N. (2004). Gamma-oryzanol from rice brain oil- A review. Indian Journal of Scientific Research, 63, 569-578.

Polthum, P. and Ahromrit, A. (2014). GABA content and Antioxidant activity of Thai waxy corn seeds germinated byhypoxia method. Songklanakarin Journal of Science Technology, 36(3), 309-316.

Prodanov, M., Sierra, I. and Vidal-Valverde, C. (1997). Effect of germination on the thiamine, riboflavin and niacin contents in legumes. Zeitschrift für Lebensmitteluntersuchung und -Forschung A, 205, 48-52.https://doi.org/10.1007/s002170050122

Rajasekaran, A., Sivagnanam, G. and Xavier, R. (2008). Nutraceuticals as therapeutic agents: A review. Research Journal in Pharmacy and Technology, 1 (4), 328-340.

Riddoch, C.H., Mills, C.F. and Duthie, G.G. (1998). An evaluation of germinating beans as a source of vitamin $\mathrm{C}$ in refugee foods. European Journal of Clinical Nutrition, 52, 115-118. https:// doi.org/10.1038/sj.ejcn.1600524

Sandström, B. (1989). Dietary pattern and zinc supply. In Mills, C.F. (ed.) Zinc in human biology, p. 350-363. New York, NY: Springer-Verlag. https:// doi.org/10.1007/978-1-4471-3879-2_22

Sangsukiam, T. and Duangmal, K. (2017). A comparative study of physico-chemical properties and antioxidant activity of freeze-dried mung bean (Vigna radiata) and adzuki bean (Vigna angularis) sprout hydrolysate powders. International Journal of Food Science and Technology, 52(9), 19711982.https://doi.org/10.1111/ijfs.13469

Sato, K., Wang, X. and Mizoguchi, K.A. (1997). A Modified form of a vitamin B12 compound extracted rom whey fermented by Lactobacillus helveticus. Journal of Dairy Science, 80, 2701-2705. https:// doi.org/10.3168/jds.S0022-0302(97)76230-1

Shankar, A.H. and Prasad, A.S. (1998). Zn and immune function: The biological basis of altered resistance to infection. American Journal of Clinical Nutrition, 68 (2), 447S-463S. https://doi.org/10.1093/ ajen/68.2.447S

Squires, M.W. and Naber, E.C. (1992). Vitamin profiles of eggs as indicators of nutritional status in thelaying 
hen: Vitamin B12 study. Poultry Science, 71(12), 275-282. https://doi.org/10.3382/ps.0712075

Tee, E.S., Mohd Ismail, N., Mohd Nasir, A. and Khatijah, I. (1997). Nutrient composition of Malaysian foods. $4^{\text {th }}$ ed. Kuala Lumpur: Institute Medical for Research.

U.S. Department of Agricultural Research Service. (2016). Nutrient Data Laboratory. USDA National Nutrient Database for Standard Reference, Release 28 (Slightly revised). Retrieved from website: http:// www.ars.usda.gov/nea/bhnrc/mafd

Van der Walt, A.M., Ibrahim, M.I., Bezuidenhout, C.C. and Loots, D.T. (2009). Linolenic acid and folate in wild-growing African dark leafy vegetables (morogo). Public Health Nutrition, 12(4), 525530. https://doi.org/10.1017/S1368980008002814

Watanabe, F., Yabuta, Y., Bito, T. and Teng, F. (2014). Vitamin B12-containing plant food sources for vegetarians. Nutrients, 6(5), 1861-1873. https:// doi.org/10.3390/nu6051861

World Health Organization (2002). Keep fit for life: Meeting the nutritional needs of older persons. Geneva: World Health Organization.

Lao, Y.X., Yu Y.Y., Li, G.K., Chen, S.Y., Wu Li, Xing, X.P., Wang, X.M., Hu, J.G. and Guo, X.B. (2019). Effect of sweet corn residue on micronutrient fortification in baked cakes. Foods, 8(7), 260. https:// doi.org/10.3390/foods 8070260

Zieliński, H., Frias, J., Piskuła, M.K., Kozłowska, H. and Vidal-Valverde, C. (2006). The effect of germination process on the superoxide dismutase-like activity and thiamine, riboflavin and mineral contents of rapeseeds. Food Chemistry, 99(3), 516-520. https:// doi.org/10.1016/j.foodchem.2005.08.014

Zuwariah, I., Hadijah, H., Aida hamimi, I. and Rodhiah, R. (2017). Effect of germination treatment in amino acids and proteins content of jackfruit seeds. Proceedings of the International Food Research Conference, 25-27 July, p. 387-390. Malaysia: Universiti Putra Malaysia. 